\title{
Results of the examinations of the W7-X pre-series target elements
}

J. Boscary (1), B. Böswirth (1), H. Greuner (1), M. Missirlian (3), B. Schedler (2), K. Scheiber (2), J. Schlosser (3), B. Streibl (1)

(1) Max-Planck-Institut für Plasmaphysik, Euratom Association, Boltzmannstr. 2, D-85748 Garching, Germany

(2) Plansee SE, Technology Center,A-6600 Reutte, Austria

(3) Association Euratom-CEA, CEA/DSM/DRFC, CEA/Cadarache, Euratom F-13108 St Paul-lezDurance, France

\section{Abstract}

The target elements of the WENDELSTEIN 7-X (W7-X) divertor are designed to sustain a stationary heat flux of $10 \mathrm{MW} / \mathrm{m}^{2}$ and to remove a maximum power of 100 kW. CFC Sepcarb ${ }^{\circledR}$ NB31 tiles are bonded to a water-cooled CuCrZr heat sink in two steps: active metal casting $\left(\mathrm{AMC}^{\circledR}\right)$ of an $\mathrm{AMC}^{\circledR}$-copper interlayer to $\mathrm{CFC}$ tiles, electron beam welding (EBW) or hot isostatic pressing (HIP) of the AMC ${ }^{\circledR}$-NB31 tiles to CuCrZr. The key target of the pre-series phase is the qualification of this bond based on a series of examinations. The introduction of silicon during the $\mathrm{AMC}^{\circledR}$ process significantly improved the strength of the joint between CFC and AMC ${ }^{\circledR}$ copper. The strength of the bond is preserved after either EBW or HIP processes. High heat flux testing carried out in the ion beam facility GLADIS exhibited a too high percentage of defective tiles. Pre-series activities have been extended to reduce the stress concentration at the interface between tiles and heat sink by optimizing the design.

Keywords: W7-X, Divertor, Plasma facing Component, Target element 


\section{Introduction}

The highly heat-loaded area of the target plates of the WENDELSTEIN 7-X (W7-X) divertor [1] spans a surface of $19 \mathrm{~m}^{2}$. It is formed by 890 water-cooled target elements (TEs) of 14 different types, with a length ranging from 250 to 595 mm, a maximum width between 50 and $61.5 \mathrm{~mm}$, and a total thickness of $30 \mathrm{~mm}$ [2]. The multiplicity of TE types is mainly due to diagnostic requirements. A twisted tape made of stainless steel, $1 \mathrm{~mm}$ thick, is placed inside the cooling channel of $9.5 \mathrm{~mm}$ diameter as a turbulence promoter to enhance the heat transfer capability. The twist ratio, which defines the length to diameter ratio for a $180^{\circ}$ twist, is four. Some elements were manufactured with a tape of a two swirl ratio. A TE is designed to sustain a stationary heat flux of $10 \mathrm{MW} / \mathrm{m}^{2}$ and to remove a maximum power of $100 \mathrm{~kW}$. A pre-series phase has been launched to qualify the design and the manufacturing route with the relevant non-destructive examinations (NDEs) for the serial production. 35 full-scale pre-series TEs have been delivered by Plansee SE. The first set of 13 elements manufactured with the first batch of CFC (Carbon Fibre reinforced Carbon) NB31 aimed to illustrate the main difficulties of the fabrication of the various geometries of TEs: the longest elements with the highest amount of 24 tiles, elements shielded by L-shaped tiles at the end facing the pumping aperture of the divertor, elements covered on some parts with L-shaped along the element to allow diagnostic windows through the target surface. Each geometry was manufactured either by EBW or by HIP. The second set of 22 elements of the same and the simplest geometry was not originally planned. It was decided after the fabrication of the second batch of CFC NB31, which did not reach the expected mechanical characteristics. In addition, dedicated probes and elements, some including artificial defects, have been manufactured to calibrate and to qualify the various NDEs throughout the fabrication. 
It is a key requirement to develop reliable NDE that can be applied after each manufacturing step of the series production. The whole manufacturing route is validated if the delivered elements withstand operating conditions similar to those in W7-X in the high heat flux (HHF) test facility GLADIS [3] without degradation of performance and integrity.

\section{Manufacturing process}

This description focuses on the bonding process between flat tiles made of CFC Sepcarb ${ }^{\circledR}$ NB31 and a CuCrZr heat sink. This joint is manufactured in two stages. In the first step, a copper interlayer is cast by active metal casting (AMC ${ }^{\circledR}$ ) onto the laser-treated surface of the tile (Fig. 1). The casting process is performed in the presence of titanium and silicon in order to generate a carbide layer, which can be wet by copper and adheres on the CFC surface. The infiltration of copper in CFC is lower than $2 \mathrm{~mm}$. The CFC thickness is $8 \mathrm{~mm}$ and the thickness of the $\mathrm{AMC}^{\circledR}-\mathrm{Cu}$ interlayer is $3 \mathrm{~mm}$. As shown in Fig. 2, the measured global thermal conductivity of the interlayer is about $150 \mathrm{~W} \mathrm{~m}^{-1} \mathrm{~K}^{-1}$ at room temperature. At this stage, the joint between copper and CFC is inspected by X-ray and visual examinations. The calibration of the X-ray facility showed that defects at the interface of a $3 \mathrm{~mm}$ diameter are reliably detected. In the second step, the AMC ${ }^{\circledR}$-NB31 tiles are joined to CuCrZr. Two technologies have been investigated: electron beam welding (EBW) and hot isostatic pressing (HIP). At this step, the joint between the tiles and the heat sink is inspected by ultrasonic. The qualification phase of the system demonstrated that 3mm diameter defects located at the interface can be reliably detected. The choice between EBW and HIP for the serial fabrication is one of the aims of the pre-series activities. In any case, the EBW technology has to be qualified since it is the only possibility to replace the 
defective tiles of completed TEs. Due to the large width of the elements (maximum $61.5 \mathrm{~mm}$ ), the welding operation is performed along the two sides of the element. The HIP process performed at $900^{\circ} \mathrm{C}$ is followed by a solution annealing treatment at a temperature of $970^{\circ} \mathrm{C}$ and a water quench. The HIP process avoids the melting phase between copper and CuCrZr inherent to EBW and does not create porosities at the interface. By applying an isostatic pressure, it may also reduce the porosity content inside CFC. Both EBW and HIP process are followed by an age-hardening treatment at a temperature of $475^{\circ} \mathrm{C}$ during 3 hours to recover the properties of $\mathrm{CuCrZr}$. At the end of the fabrication, the bond between the heat sink and the CFC tiles is inspected by thermography methods.

\section{Examination of CFC material}

The production of three different batches for a total amount of about $1000 \mathrm{~kg}$ has been completed by Snecma Propulsion Solide (France). CFC Sepcarb® NB31 is a 3D anisotropic composite. This material is characterized by a complex manufacturing route [4] and is intrinsically rather inhomogeneous. Between CFC batches, the delivered material showed a large scatter in the ex-pitch tensile strength. The scatter range is between 50 and $180 \mathrm{MPa}$ (Fig. 3.a) [5]. Scattered values were also measured for the thermal conductivity in the same fibre direction (Fig. 3.b) [5, 6]. At room temperature, it varies between 250 and $400 \mathrm{~W} \mathrm{~m}^{-1} \mathrm{~K}^{-1}$; this scatter is less noticeable at $800^{\circ} \mathrm{C}$.

An additional pre-series of 22 TEs was produced to decide whether the batch 2 of CFC NB31 material could be used for the serial fabrication [7]. Eleven elements were manufactured by HIP and eleven elements by EBW. The purpose was to study the effect of the reduced tensile strength in the ex-pitch fibre direction on the 
manufacturing process and on the performance of the bond. The whole production of CFC NB31 was accepted to avoid a delay in the fabrication of the TEs. Experimental results [8] did not show any effect in the quality of the bond that could be attributed to the CFC batch, using either EBW or HIP technology.

\section{Characterization of the bond}

The basic problem is the accommodation of the large mismatch in the coefficient of thermal expansion between CFC and copper, while achieving and maintaining a good heat transfer during cyclic thermal loads. The $\mathrm{AMC}^{\circledR}-\mathrm{Cu}$ interlayer acts as a transition zone for normal and shear stresses and strains. The mechanical performance of the bond was characterized at Plansee SE by a push-test in the shear direction at room temperature [9]. This mechanical destructive test was also performed after a fatigue process: the samples were heated from 20 to $450^{\circ} \mathrm{C}$ followed by an abrupt waterquench down to $20^{\circ} \mathrm{C}$. This procedure was repeated 20 times.

As shown in Fig. 4, the introduction of silicon in the $A M C^{\circledR}$ process improves significantly the bond strength. After water-quench, this improvement is preserved. Fig. 5 compares the characteristics of the bond between the tile and the heat sink at different stages. The strength of the AMC ${ }^{\circledR}$-NB31 tile is roughly $40 \%$ higher than the one of the raw CFC NB31 material at room temperature. For the elements manufactured with the CFC from batch 1, the HIP process was performed at a temperature of $900^{\circ} \mathrm{C}$ and a pressure of $80 \mathrm{MPa}$. After both EBW and HIP processes, the characteristics of the bond are preserved. A higher margin of roughly $30 \%$ is reached with HIP and may favor the selection of this technology for the serial fabrication. The same analysis was carried out with elements manufactured with the CFC from batch 2, which is characterized by a much lower tensile strength in the ex- 
pitch fibre direction ( factor 2 ) than batch 1 . In this case, HIP was performed at a pressure of $70 \mathrm{MPa}$. There was no noticeable difference found in the mechanical behavior of the bond (Fig. 6). The reduction of the pressure applied during the HIP process did not alter the mechanical response of the joint. After water-quench, the measurements did not show any degradation of the bond.

\section{Strategy for the bond qualification and optimization}

All pre-series TEs have been tested in GLADIS. The results of the HHF tests exhibited a high percentage of defective tiles, indicated by hot spots at the lateral border of the CFC surface. No tiles were detached during the thermal cycling tests. Among the 210 tiles tested of the additional pre-series of TEs, $70 \%$ have been accepted, 15\% rejected and 15\% still needs additional investigations. Visual inspections after HHF tests have mostly correlated these spots to the initiation and /or propagation of cracks at the interface between CFC and copper. This behavior indicates an insufficient margin in the design to cope with the stress level at the critical AMC ${ }^{\circledR}$ interface. By means of non-linear finite element computations, the following most effective options are being investigated:

- The reduction of the thermal stresses by increasing the thermal conductivity of the $\mathrm{AMC}^{\circledR}$-Cu interlayer replaced by a bi-metallic copper layer. It consists of an $\mathrm{AMC}^{\circledR}$ $\mathrm{Cu}$ layer of 0,4 mm thickness and a pure copper layer of $2 \mathrm{~mm}$;

- The reduction of the size of the tiles from a maximal width of $\sim 62 \mathrm{~mm}$ down to $\sim 20$ $\mathrm{mm}$;

- The rotation of the needling direction into the lateral direction. An important issue of the pre-series phase is the definition of the acceptance criteria with a special focus on this bond to be applicable to the conditions of the serial 
fabrication. NDE based on thermography methods are applied before ("prediction mode”) and after (“correlation mode”) the HHF tests carried out on GLADIS [10]. It is intended in this way to evaluate and define NDE fault criteria that permit reliable predictions to achieve the nominal heat flux requirements in $\mathrm{W} 7-\mathrm{X}$.

\section{Conclusion}

A major issue of the pre-series activities is the qualification of the 2-step bond between CFC NB31 tiles and CuCrZr heat sink: the joint between CFC and the interlayer by $\mathrm{AMC}^{\circledR}$, and the joint between $\mathrm{AMC}^{\circledR}$-tiles and $\mathrm{CuCrZr}$ by EBW or HIP. The strength of the joint between CFC and $\mathrm{AMC}^{\circledR}$-copper is significantly improved by introducing silicon during the $A M C^{\circledR}$ process. The strength of the bond is preserved after either EBW or HIP processes.

HHF test results performed in GLADIS showed a too high percentage of defective tiles to start the fabrication. No tiles were detached during the thermal cycling tests. Typical defects are the propagation of cracks in CFC at the lateral edge of the interface between CFC and copper. The pre-series activities will be extended to increase the strength of this bond. Efforts are focused on the reduction of the stresses at this critical interface by improving the design. The selected option will be validated by additional pre-series TEs to be tested on GLADIS, and examined by thermography methods. 


\section{References}

[1] H. Renner, D. Sharma, J. Kißlinger, J. Boscary, H. Grote, R. Schneider, Physical aspects and design of the W7-X divertor, Fus. Sci. Technol. 46 (2) (2004) 318-326. [2] J. Boscary, H. Greuner, B. Mendelevitch, B. Schedler, K. Scheiber, J. Schlosser, B. Streibl, Applied technologies and inspections for the W7-X pre-series target elements, Fus. Eng. And Design 75-79 (2005) 451-455.

[3] H. Greuner, H. Bolt, B. Böswirth, T. Franke, P. McNeely, S. Obermayer, N. Rust, S. Süß, Design, performance and construction of a $2 \mathrm{MW}$ ion beam test facility for plasma facing components, Fus. Eng. and Design 75-79 (2005) 345-350.

[4] M. Merola, , C. H. Wu and the EU participating Team, Development of carbon materials and plasma facing components for ITER, Phys. Scripta T 111 (2004) 152156.

[5] I. Berdoyes, Characterization of the IPP productions of CFC NB31, Snecma Propulsion Solide reports (2003, 2004, 2006).

[6] P. Majerus, J. Compan, D. Pitzer, M. Rödig, Measurement physical and mechanical properties of CFC delivered by SNECMA, Forschunszentrum Jülich report, EFDA Task TW2-TVM-CFCQ2 (2004).

[7] J. Schlosser, A. Durocher, T. Huber, P. Chappuis, P. Garin, W. Knabl, B. Schedler, Material properties and consequences on the quality of tore supra plasma facing components, J. Nucl. Materials 307-311 (2002) 686-690.

[8] H. Greuner, B. Böswirth, J. Boscary, A. Plankensteiner, B. Schedler, High heat flux tests of the WENDELSTEIN 7-X pre-series target elements - Experimental evaluation of the thermo-mechanical behaviour (this conference). 
[9] B.Schedler, T.Huber, E.Eidenberger, T.Scheu, R.Pippan, H.Clemens, Methods to determine the joint strength of $\mathrm{C} / \mathrm{C}$ to copper joints (this conference).

[10] M. Missirlian, H. Traxler, J. Boscary, A. Durocher, J. Schlosser, B. Schedler, P. Schuler, Infrared thermography inspection methods applied to the target elements of W7-X divertor (this conference). 


\section{Figure captions}

Fig. 1. Interface between CFC NB31 and AMC ${ }^{\circledR}$-Cu. Laser-structured surface of CFC Fig. 2: Measurement of the thermal conductivity of the $A M C^{\circledR}-\mathrm{Cu}$ interlayer Fig.3.a. Measurement of the tensile strength of the different CFC NB31 batches in the ex-pitch fibre direction at room temperature

Fig.3.b. Measurement of the thermal conductivity of the different CFC NB31 batches in the ex-pitch fibre direction

Fig. 4. Shear strength measurements of $A M C^{\circledR}$-tiles at room temperature - Effect of silicon

Fig. 5. Shear strength measurement at room temperature - Batch 1 CFC - The grey zone shows minimum and maximum values.

Fig. 6. Shear strength measurement at room temperature - Batch 2 CFC - The grey zone shows minimum and maximum values. 


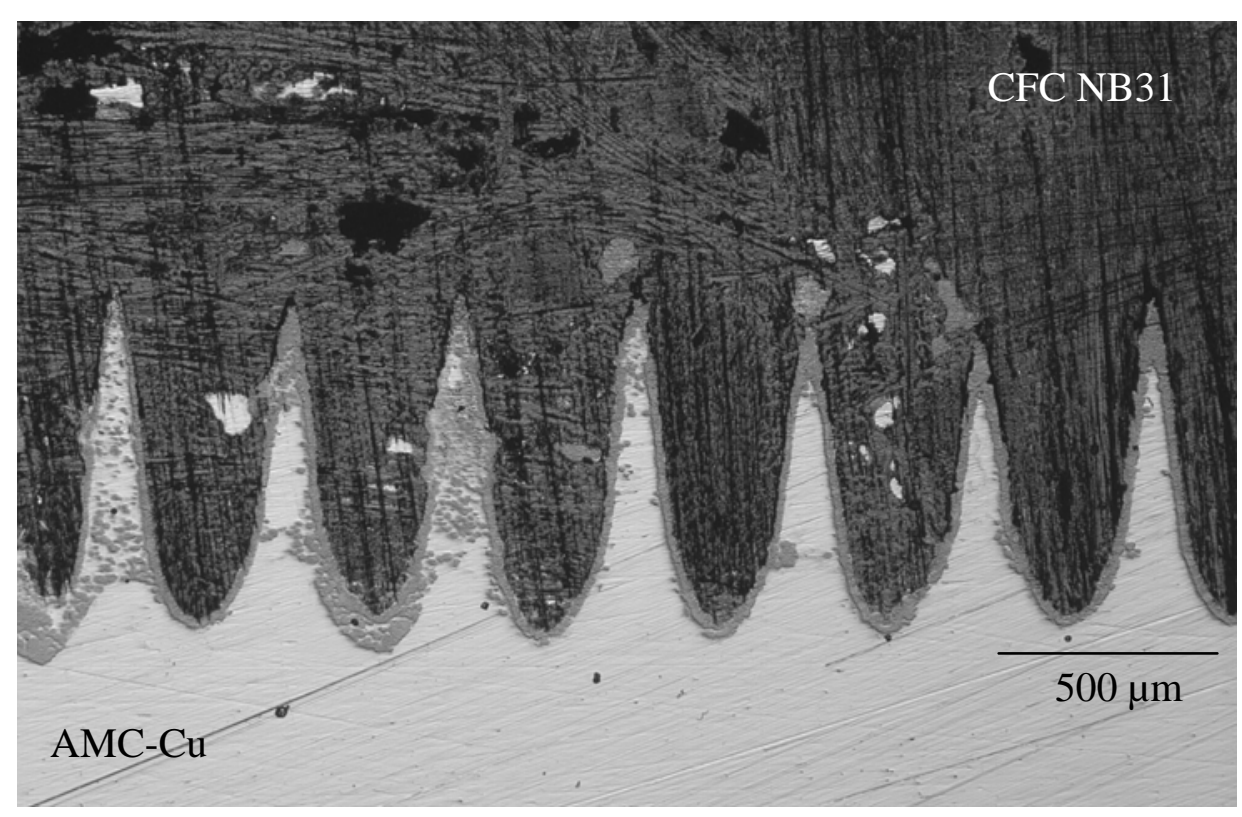

Fig. 1.

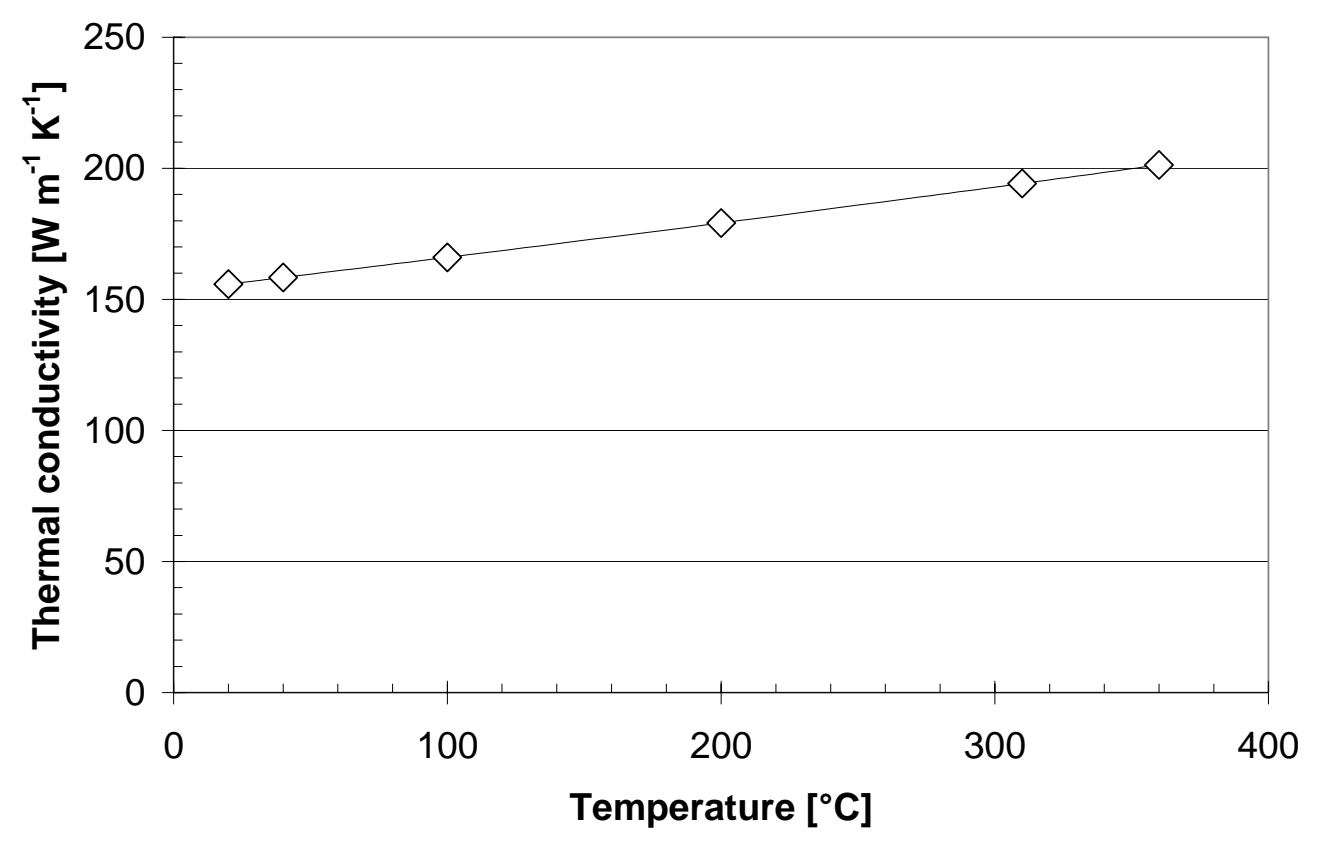

Fig. 2. 


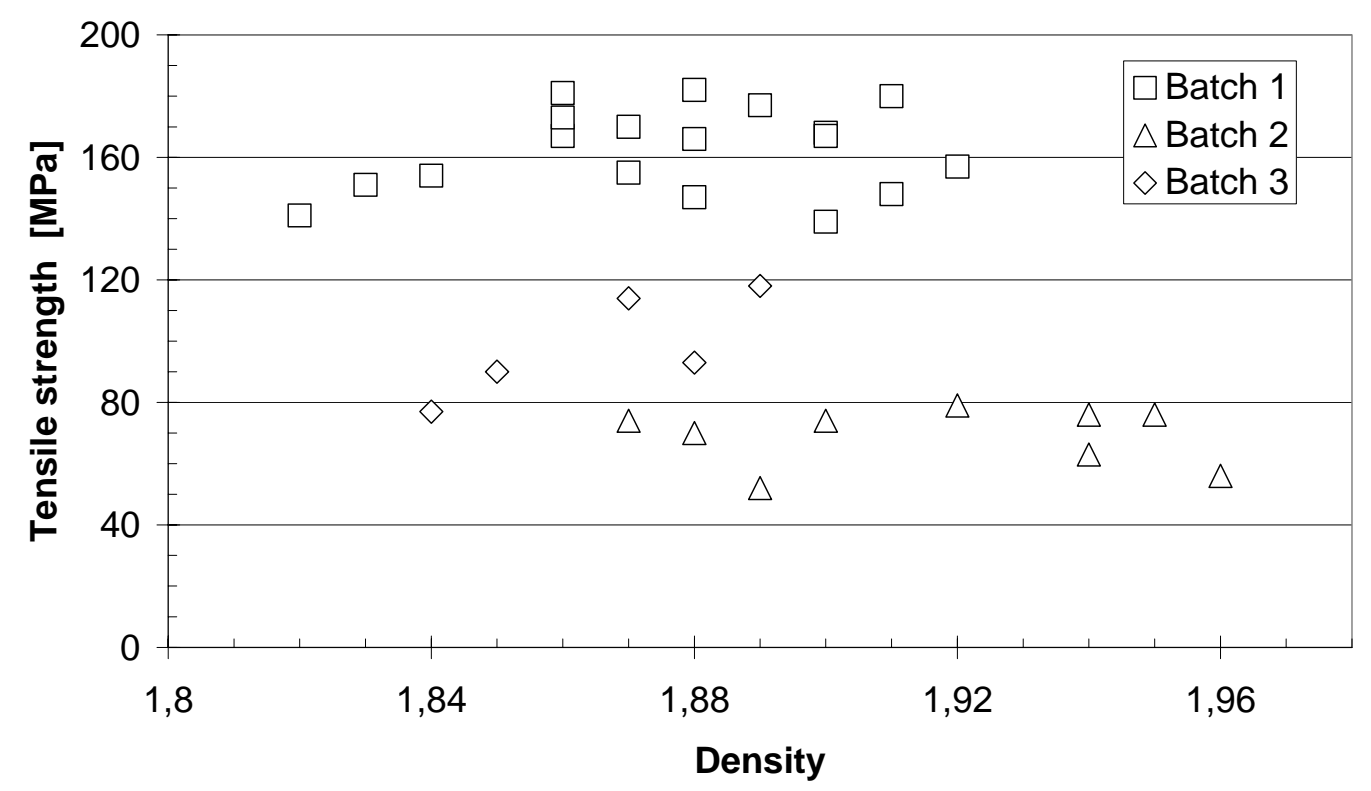

Fig.3.a.

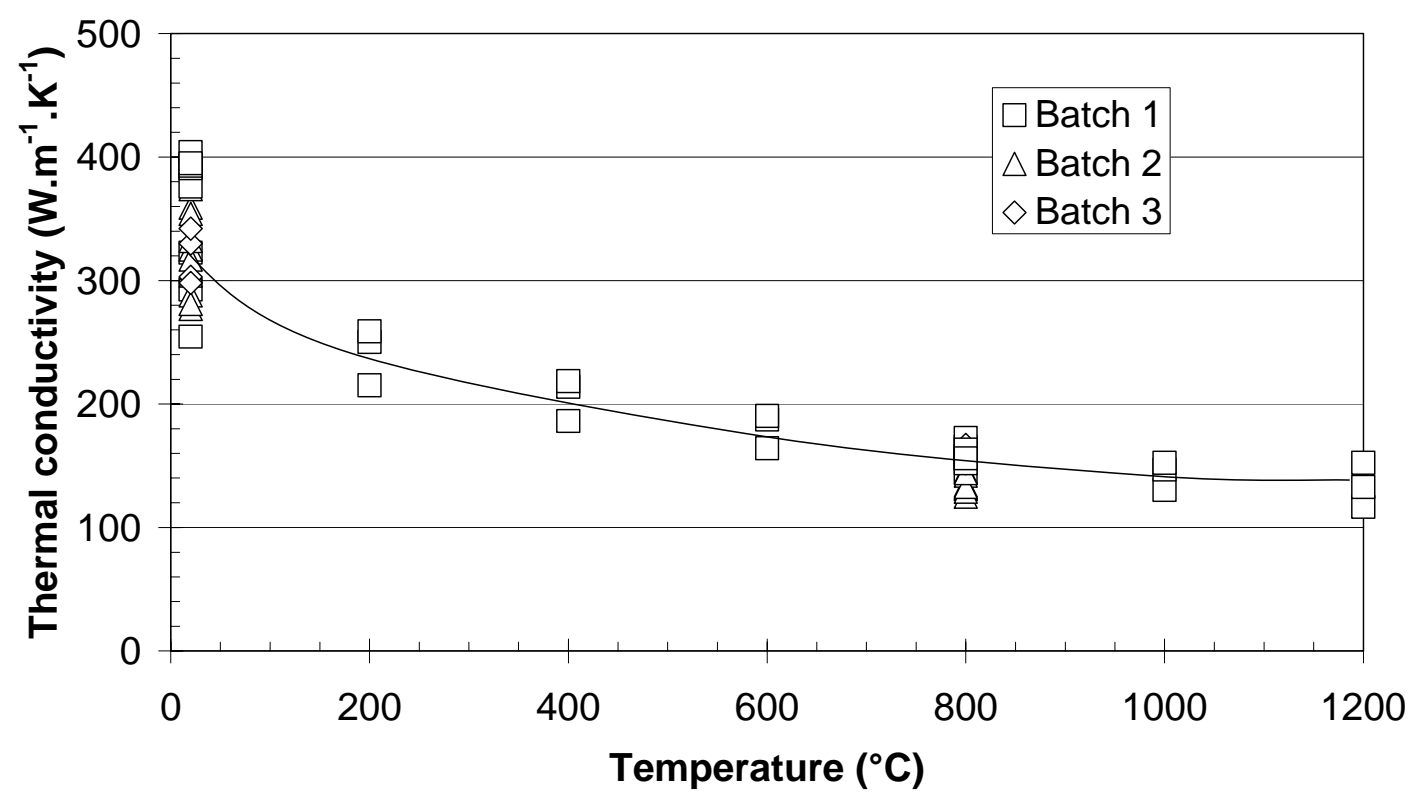

Fig.3.b. 


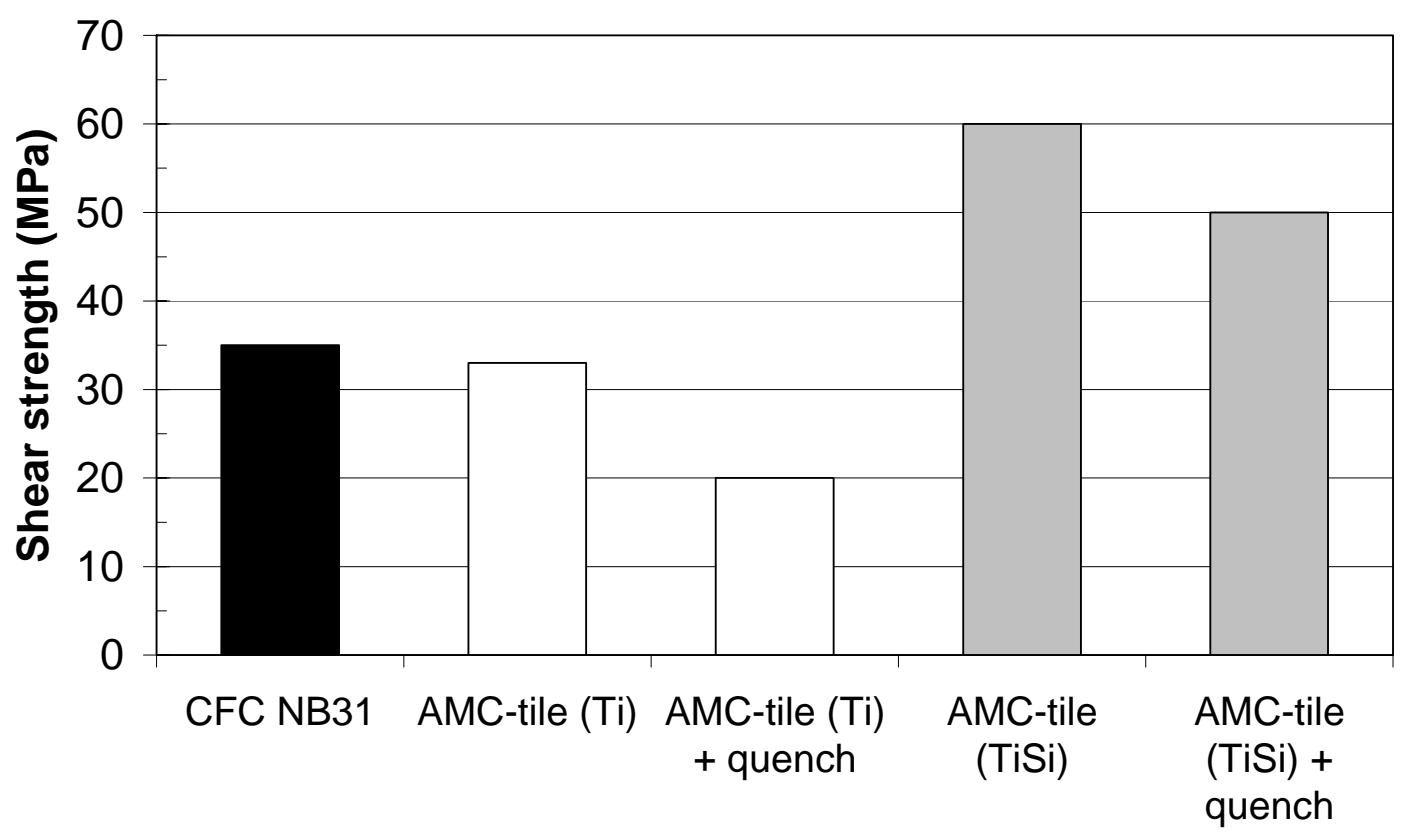

Fig. 4.

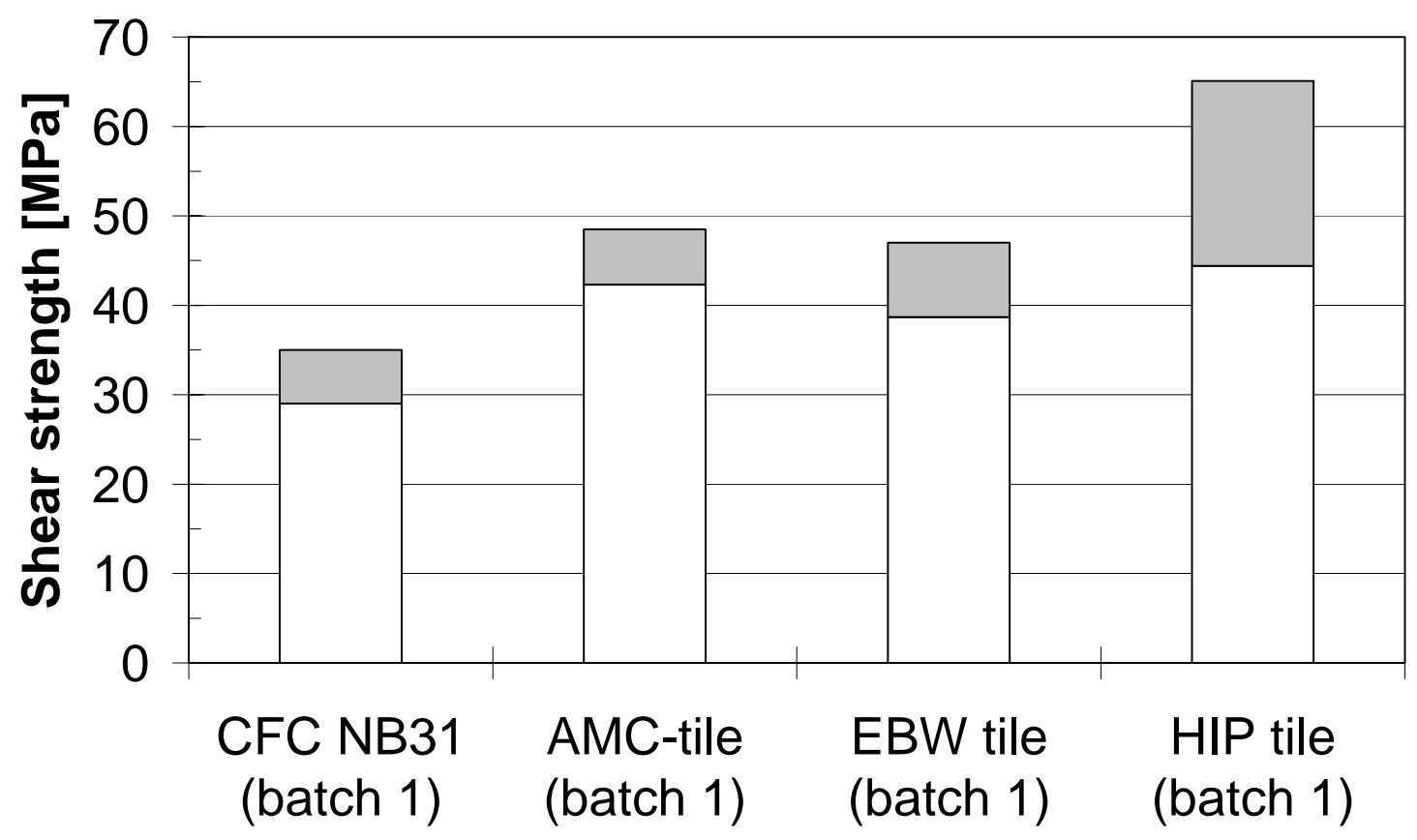

Fig. 5. 


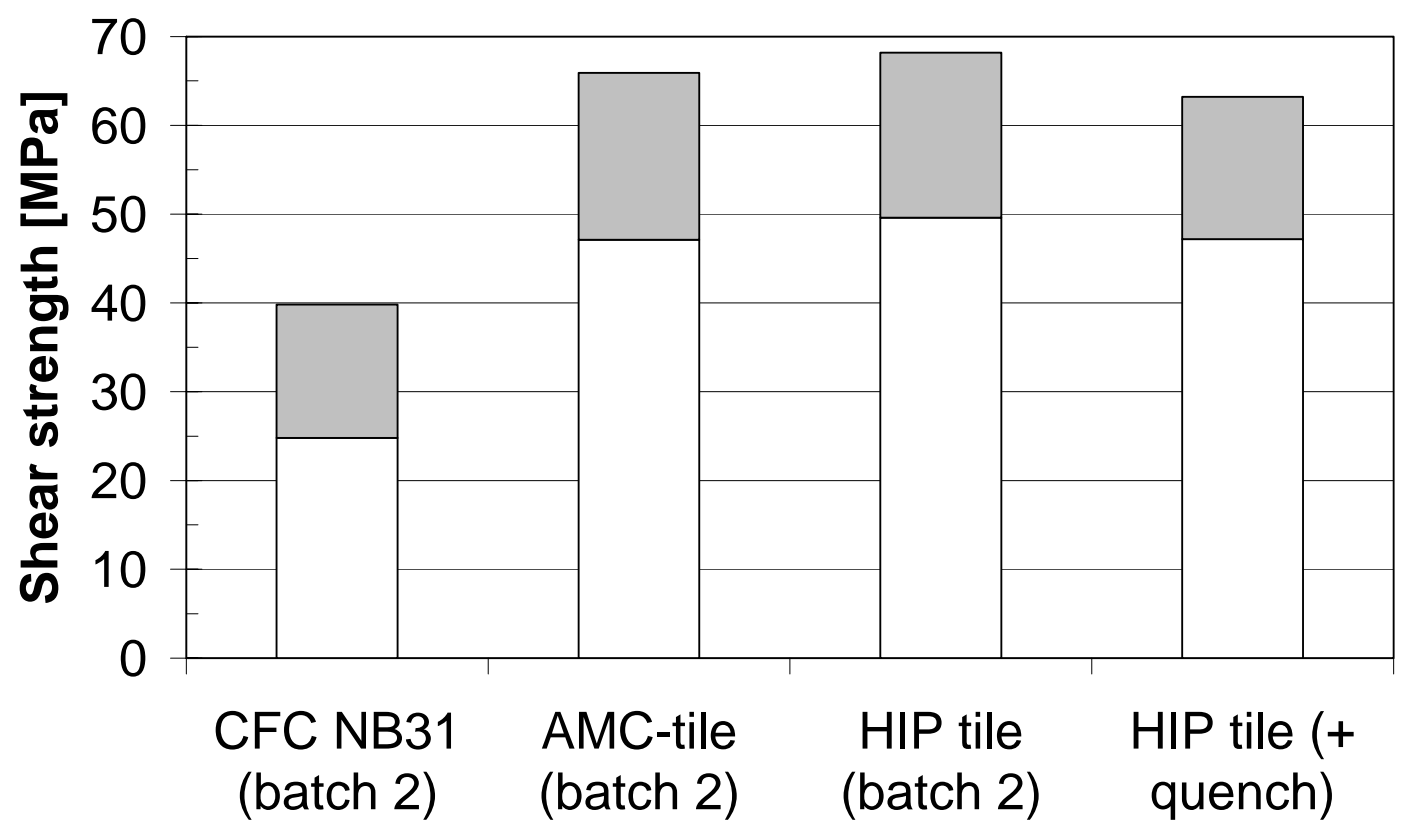

Fig. 6. 